\title{
Conventional Shaping the Edges of Thick Steel Plates After Welding Process
}

\author{
Waldemar MATYSIAK*, Miroslav DUSPARA, Josip CUMIN, Ivan SAMARDŽIĆ
}

\begin{abstract}
The paper presents the results of theoretical analysis and experimental details of shaping the edges of thick steel plate using conventional technology. The aim was to determine the influence of holes laser cutting on the shape and technological possibilities of the steel sheet edges flanging. In this study numerous computer simulations were made in order to design a process guaranteeing obtaining a proper product. During this simulation of material flow kinematics, strain and damage criterion distributions and shaping were analyzed. On the basis of the obtained results, the analysis of limiting phenomena, which could appear during the process, was made. Experimental tests in industrial conditions according to designed technology were carried out. Good quality of specimens shaping was obtained. It was found that shaping the edges of thick steel plate after welding process is possible.
\end{abstract}

Keywords: conventional shaping; metal working; shaping thick steel plate; welding process

\section{INTRODUCTION}

Shaping drawpieces by metalworking processes has many advantages, both technological and economical. Shaping the edges of holes can be used, among others, to obtain a sufficiently secure threaded connection or interference with other parts. Two types of shaping the edges can be distinguished: shaping the edges of holes (burring) and shaping the outer edges of drawpieces (flanging) [1-4]. They differ in the nature of deformation, the development of stress and character of destination. The subject of this paper are the research problems on burring (holes in cylindrical surface) in thick metal plates after welding process. The thickness of metal plates was $8 \mathrm{~mm}$. The burring of the holes can replace the stamping and cutting operations of the bottom. The use of burring the holes in the production of parts with a large flange is particularly advantageous when stamping is difficult and requires many operations and treatments [5-10]. One of the factors limiting the burring process is the deformability of the material being processed. The limit value of the deformation coefficient in this process depends on many factors with varying degrees of impact on the process, mainly from: properties of the applied material, shape of tools (working shape of parts of the seal), process to make a hole, variations in the coefficient of friction, initial hole diameter. The analytical determination of the basic values of the holes burring process, and above all the permissible values of transferred stress, does not always give satisfactory results due to the necessity of simplifying assumptions according to the state of deformation in individual area and frictional resistance-also variation during the burring process. In addition, it is very difficult to properly consider the way the hole is made. Due to the significant development of computer simulations of the course of metal forming processes taking into account material and geometrical properties, the presented paper attempts a computer simulation of the holes burring process carried out using the MSC.MarcMentat software.

\section{METHODOLOGY}

As part of this paper, the program of experimental research and computer simulation of the process of burring the edges of holes was planned, including: determination of mechanical properties of the tested material in a static tensile test, determination of the work-hardening curve for test material for their matrix and HAZ (Heat Affected Zone) in the Rastiegayev's test, measurements of matrix hardness and HAZ of material by Vickers testing, metallographic investigation, burring tests, numerical modeling of the burring process. Samples in the form of discs with a diameter of $160 \mathrm{~mm}$ were used for the tests (Fig. 1), which were made of $170 \mathrm{~mm}$ squares and laser cut from Bw11 steel grade strips. The choice of material was made according to that used for high-pressure products in the engineering industry. However, the burring holes edges can be used to shape pipe ends subjected to high pressure. The thickness of the plate was $g_{0}=8 \mathrm{~mm}$, the gap between the punch and the matrix $z=g_{0}$ and the radius of curvature of the matrix $r_{m}=8 \mathrm{~mm}$. Samples with drilled holes of $\varnothing 21$ $\mathrm{mm}$ diameter were used for welding tests. For the tests, punch with diameters of $\varnothing 50 \mathrm{~mm}$ was used, with a spherical shape of the working part (Fig. 2) and the burring tools were installed on the PYE press with the pressure of 250 $\mathrm{Mg}$. Before the burring process, the discs were cut and the surfaces prepared for the welding process. Two welding methods were used-covered electrode and MIG. Then the surfaces of the discs connected by welding were subjected to the milling process. A die with an $ø 66 \mathrm{~mm}$ hole was used. Coefficient of the burring was obtained according to the following Eq. (1):

$k_{w}=\frac{d_{0}}{d}$

where: $d_{0}$ - diameter of the hole, $d$-diameter of the stamp.

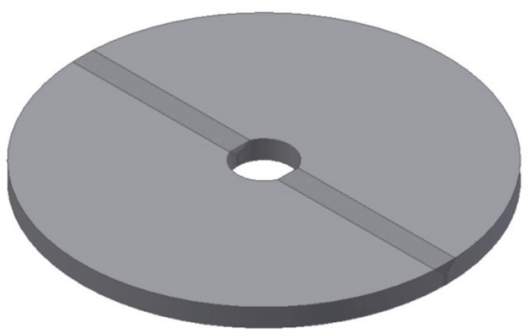

Figure 1 Sample for the investigation 


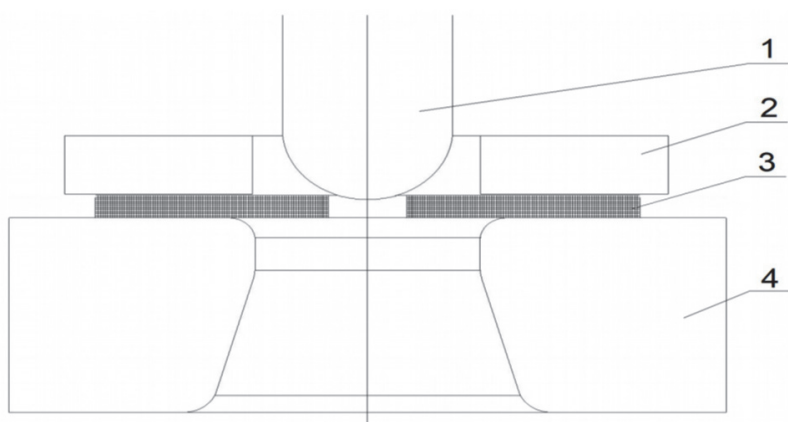

Figure 2 Investigations and productions tools (1-punch, 2-flange holder, 3-metal plate, 4-burring die)

The chemical composition of metal plates used for burring process is shown in Tab. 1.

\begin{tabular}{|c|c|c|c|c|c|}
\hline \multirow{2}{*}{ Material } & \multicolumn{5}{|c|}{ Chemical composition / \% } \\
\hline & $\mathrm{C}$ & Mn & Si max & $\mathrm{P} \max$ & $\mathrm{S} \max$ \\
\hline \multirow{3}{*}{ Bw11 } & $0,09 \div 0,13$ & $0,3 \div 0,5$ & 0,13 & 0,025 & 0,025 \\
\hline & Cr max & Ni max & $\mathrm{Al}$ & $\mathrm{Cu}$ & \\
\hline & 0,2 & 0,2 & $0,03 \div 0,07$ & - & \\
\hline
\end{tabular}

The PYE 250 hydraulic press was used for burring process. The parameters of this machine are shown in Tab. 2.

Table 2 Chemical composition of Bw11 steel used

\begin{tabular}{|l|l|}
\hline Nominal pressure & $2500 / \mathrm{kN}$ \\
\hline Speed of slider & $20 / \mathrm{mm} / \mathrm{s}$ \\
\hline Stroke of slider & $500 / \mathrm{mm}$ \\
\hline Pressure in hydraulic system & $20 / \mathrm{MPa}$ \\
\hline Dimensions of press table & $900 \times 700 / \mathrm{mm}$ \\
\hline
\end{tabular}

The investigations began with determining the mechanical properties of steel. The tensile tests were carried out on the Instron 4483 testing machine. Young's modulus values and other strength properties of the samples were obtained using the Blue Hile 2 computer system, an integral part of the test stand. After the tests, stress-strain curves and work-hardening curves were obtained. The averaged results obtained from the tensile test are as follows: $R_{e}=295 \mathrm{MPa}, R_{m}=380 \mathrm{MPa}, E=213,8$ $\mathrm{GPa}$. After the Rastiegayev's tests, the work-hardening curves described by the equations were obtained $\sigma_{p}=$ $552 \varphi^{0,24}$ for the matrix of Bw11 steel. Because it is difficult to determine surface shares of HAZ and matrix, and it is practically impossible to take samples for stretching from $\mathrm{HAZ}$, parameters of strengthening function for HAZ were determined indirectly by measuring microhardness changes $(\mu H V)$ of samples in warp and HAZ (Tab. 3).

Table 3 Hardness values HV0,3 for the tested materia

\begin{tabular}{|c|c|c|c|c|c|c|}
\hline \multicolumn{2}{|c|}{ Material/Measurement } & 1 & 2 & 3 & 4 & 5 \\
\hline \multirow{2}{*}{ Bw11 } & matrix & 114,6 & 114,8 & 116,6 & 113,8 & 114,4 \\
\cline { 2 - 7 } & HAZ & 190,3 & 190,6 & 193,5 & 188,9 & 189,9 \\
\hline
\end{tabular}

Then, the corresponding results of microhardness measurements were correlated using the following dependence (2) [5-6]:

$\sigma_{p(\mathrm{HAZ})}=\sigma_{p(\text { matrix })} \frac{\mu H V_{(\mathrm{HAZ})}}{\mu H V_{(\text {matrix })}}$
Using the above formula the parameters of the workhardening curve function for $\mathrm{HAZ}$ were determined $\frac{\mu H V_{(\mathrm{HAZ})}}{\mu H V_{(\text {matrix })}}=1,66$ and $\sigma_{p}=916 \varphi^{0,24}$ for the fusion weld of Bw11 steel.

The reason for the differentiation of sheet properties depending on the direction of their examination-anisotropy of properties is the varied density of atomization of individual directions and crystallographic planes. Requirements for sheet metal in many applications (car bodies, cans, cold pressed machine parts) come down to cold formability that allows parts to be shaped by pressing without any defects whose removal would increase the cost of the manufacturing process. An extremely important parameter of cold rolled and annealed sheets is crystallographic texture. The crystallographic texture of the sheet affects the distribution of deformation and plastic flow during the shaping of sheet products. Normal anisotropy is characterized by the effect of crystallographic texture on deformation in a direction normal to the sheet plane. Normal anisotropy is very important from the point of view of cold plastic deformation (it is the basic parameter of deep-drawing plates). Samples for determining the plastic anisotropy coefficient were taken at an angle of $0^{\circ}, 45^{\circ}$ and $90^{\circ}$ relative to the rolling direction of the sheet metal and measurements were made after an elongation of $20 \%$. The values of plastic anisotropy coefficients were calculated from the dependence (3):

$r=\frac{\ln \left(\frac{b_{0}}{b}\right)}{\ln \left(\frac{l b}{l_{0} b_{0}}\right)}$

and: $r_{0 / 20}=1,424 ; r_{45 / 20}=1,344 ; r_{90 / 20}=1,514$.

\section{TESTS RESULTS AND ANALYSIS}

The tests began with burring the edges of holes. After fixing the welding metal plate, the tests were started. After each test, the extrusion height was measured at four points on the edge-every $90^{\circ}$ and the smallest edge thickness-at the same points. $G_{1}$ thickness measurements and $h$ edging heights were made with an accuracy of $0,05 \mathrm{~mm}$ (Fig. 3.).

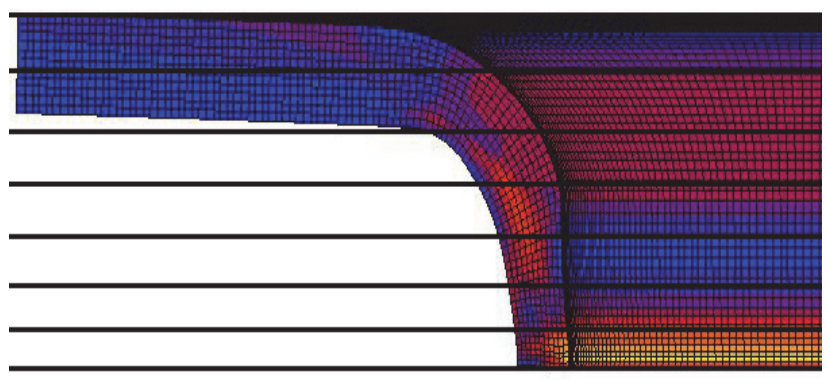

Figure 3 Diagram of thickness measurement of burring edges

The measurement results are presented in Tab. 4. The results represent the average of 15 burring tests. 
Table 2 Results of burring the edges

\begin{tabular}{|c|c|c|c|c|}
\hline Material & $\begin{array}{c}\text { Thickness } \\
g_{0} / \mathrm{mm}\end{array}$ & $\begin{array}{c}\text { Hole } \\
\text { diameter } \\
d_{0} / \mathrm{mm}\end{array}$ & $\begin{array}{c}\text { Flange thickness after } \\
\text { burring } g_{1} / \mathrm{mm}\end{array}$ & $\begin{array}{c}\text { Flange } \\
\text { height } \\
h / \mathrm{mm}\end{array}$ \\
\hline \multirow{3}{*}{ Bw11 } & 8 & 23 & 5,8 & 28,3 \\
\cline { 2 - 5 } & 8 & 21 & 5,6 & 29,6 \\
\cline { 2 - 5 } & 8 & 19 & 5,2 & 30,5 \\
\hline
\end{tabular}

Measurement results regarding thickness in relation to the flange height for the tested steel are shown in the drawing (Fig. 4).

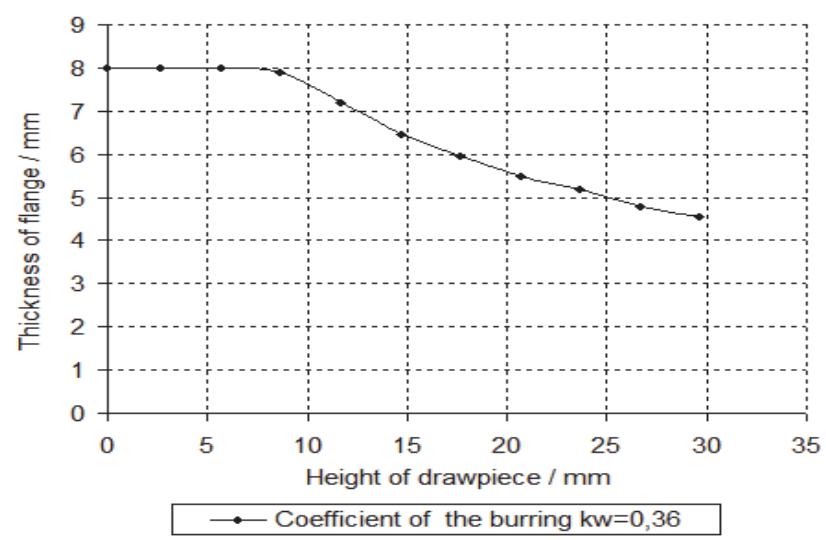

Figure 4 Diagram of thickness distribution as a function of the height

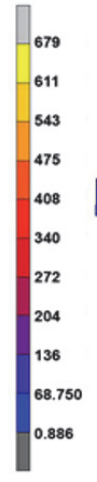

In order to perform numerical modeling for samples, the automatic reconstruction of the finite element mesh during the calculations was used. The Coulomb friction model and friction coefficients between individual tools and steel samples equal to 0,13 were used; 0,4 and 0,05 . The FEM (Finite Element Method) model of the 3D process is shown in Fig. 5.

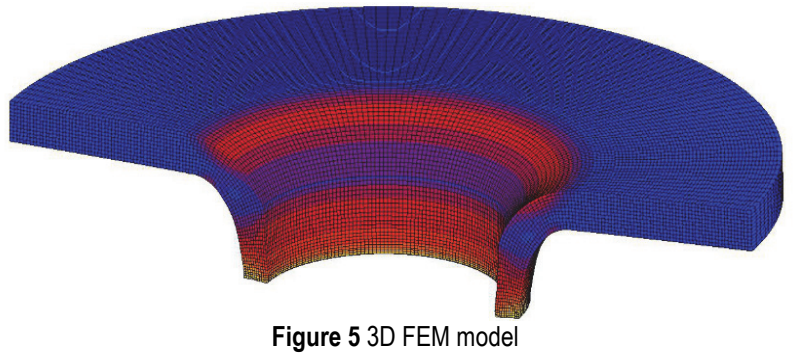

Fig. 6 shows the distributions of reduced stresses in drawpiece. Coefficient of friction $\mu=0,13$ Fig. 7 shows plastic strain distributions. a)

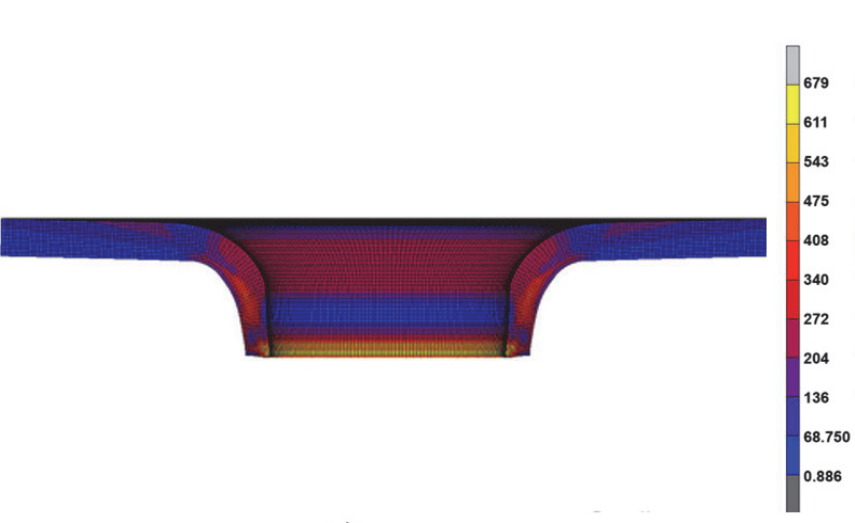

Figure 6 Distribution of the reduced stresses

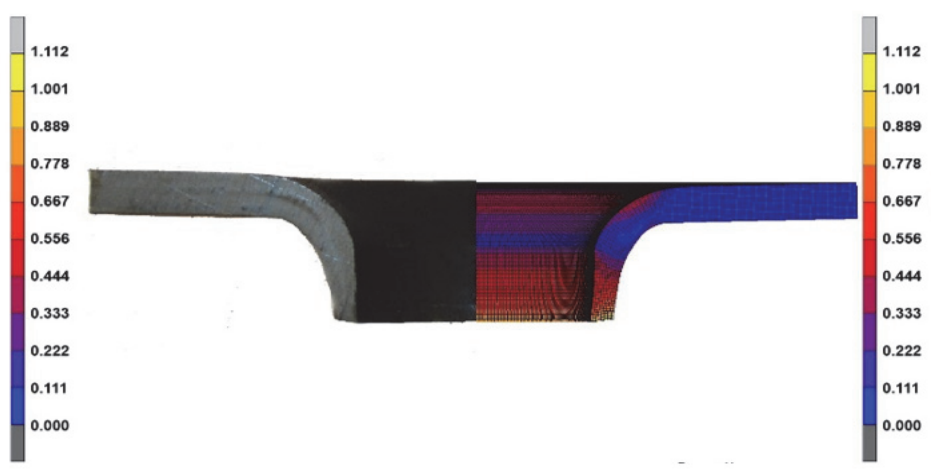

a)

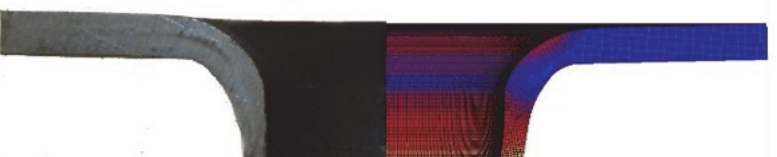

b)

Figure 7 Plastic strains distribution

Metallographic tests were performed to illustrate changes in the microstructure at HAZ. For Bw11 steel, the structure of the HAZ zone just near the welding surface is martensitic, while the matrix structure of Bw11 steel is ferritic with a small proportion of perlite with coagulated cementite particles. 


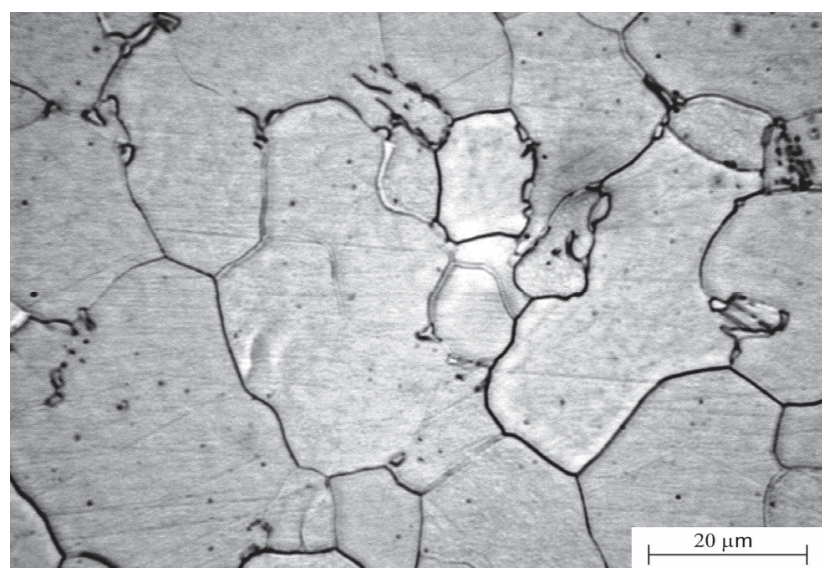

Figure 8 Bw11 steel matrix structure-ferritic with a small proportion of perlite with coagulated cementite particles

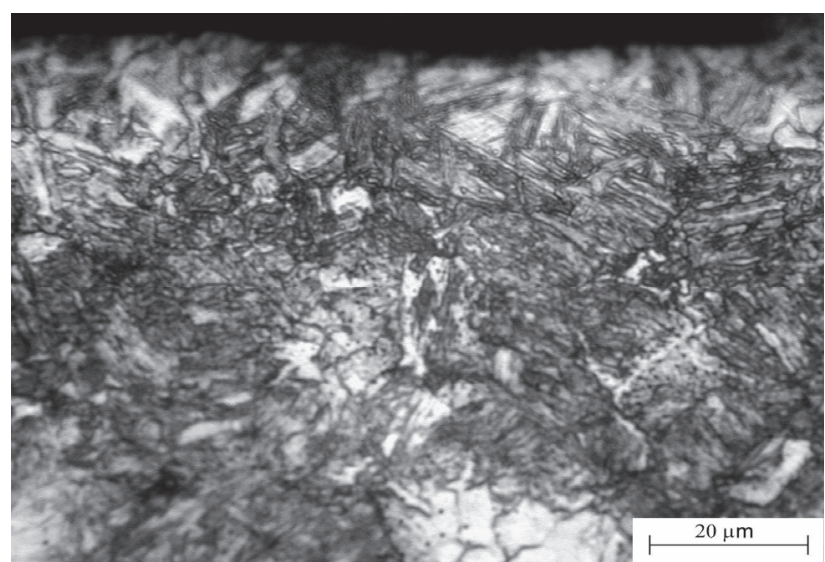

Figure 9 HAZ martensitic structure after Bw11 steel welding

In addition to the occurrence of HAZ, it has been found that surface roughness around the holes may have a significant effect on cracking. It was assumed that the surface roughness after laser cutting would be greater than the surface roughness after drilling. Roughness measurements were made with the Hommel Werke T8000 $\mathrm{RC}$ profilometer. The surface roughness of the drilled holes was measured in a direction perpendicular to the axis of the hole, while the surface roughness of the laser cut holes was measured in a direction perpendicular to the axis of the laser beam. The results were developed with the help of HOMMEL-ETAMIC TURBO WAVE V7.36 computer software. The following average values of parameter Ra of tested steels were obtained: drilling $R a=1,325 \mu \mathrm{m}$, laser cutting $R a=4,937 \mu \mathrm{m}$.

\section{CONCLUSIONS}

The analysis of the results allows stating that the material accepted for testing may be burring to the adopted values of burring coefficients, after the plate welding process. Analyzing graph of flange thickness change at the height of the flange shown, it should be stated that: - as the height of the flange, the thickness of the wall, the flange decreases, the differences in the height of the flange and the thickness variation can be important for the design of the actual burring process. The presented stresses distribution shows that the increase in the stress values can be observed in places where the flat surface is curved, and the highest values reach the minimum edge thickness. The plastic strains distribution presented shows their unevenness. As in the case of the distribution of reduced stresses, the greatest values of plastic deformation can be observed in the places where the flat surface moving in the curved and in the areas of the largest edge rubbing. Simulation tests have also proved that the friction conditions significantly affect the geometric dimensions of the flanged edge in terms of its thickness and height. In particular, it was shown that increasing the value of the coefficient of friction increases the height of the flange, while reducing its thickness. Thus, a variation in the friction conditions can be used to obtain different geometric dimensions of the burring.

\section{REFERENCES}

[1] Li, D., Luo, Y., Peng Y., \& Hu, P. (2007). The numerical and analytical study on stretch flanging of V-shaped sheet metal. Journal of Materials Processing Technology, 189(1-3), 262267. https://doi.org/10.1016/j.jmatprotec.2007.01.035

[2] Seymen, Y., Güler, B., \& Efe, M. (2016). Large Strain and Small-Scale Biaxial Testing of Sheet Metals. Exp Mech., 56, 1519-1530. https://doi.org/10.1007/s11340-016-0185-7

[3] Kocańda, A. (2000). Some selected directions of advance in plastic working. Mechanical Review, 3, 6-11.

[4] Kleiner, M., Homberg, W., \& Brosius, A. (1999). Process and control of sheet metal hydroforming. Advanced Technology of Plasticity, 2, 1243-1252.

[5] Rojek, J., Hyrcza-Michalska, M., Bokota A., \& Piekarska, W. (2012). Determination of mechanical properties of the weld zone in tailor-welded blanks. Archives of Civil and Mechanical Engineering, 12, 156-162. https://doi.org/10.1016/j.acme.2012.04.004

[6] Rojek, J. Hyrcza-Michalska, M., Bokota, A., \& Piekarska W. (2010). Methods for determining the mechanical properties of laser-welded joints in batches stamping. Mechanical Review, 11, 13-20.

[7] Piela, A., Hyrcza, M., \% Lisok, J. (2001). Laser weld model in tailored blanks. Mechanical Review, 4.

[8] Kim, S-Y, Tsuruoka, K., \& Yamamoto, T. (2014). Effect of Forming Speed in Precision Forging Process Evaluated Using CAE Technology and High Performance Servo-press Machine. Procedia Engineering, 81, 2415-2420. https://doi.org/10.1016/j.proeng.2014.10.343

[9] Khalfallah, A. (2014). Experimental and numerical assessment of mechanical properties of welded tubes for hydroforming. Materials \& Design, 56, 782-790. https://doi.org/10.1016/j.matdes.2013.11.051

[10] Xia, L., Xu, Y., El-Aty, A. A. et al. (2019). Deformation characteristics in hydro-mechanical forming process of thinwalled hollow component with large deformation: experimentation and finite element modeling. Int $J A d v$ Manuf Technol 104, 4705-4714.

https://doi.org/10.1007/s00170-019-04346-1 


\section{Contact information:}

Waldemar MATYSIAK, PhD. Eng. assistant professor (Corresponding author)

Poznan University of Technology,

3 Piotrowo Street, 60-965 Poznan, Poland

E-mail:waldemar.matysiak@put.poznan.pl

Miroslav DUSPARA, PhD. Eng, assistant professor

Mechanical engineering faculty in Slavonski Brod,

University of Slavonski Brod,

35000 Slavonski Brod, Croatia

E-mail: mduspara@unisb.hr

Josip CUMIN, PhD. Eng, assistant professor

Mechanical engineering faculty in Slavonski Brod,

University of Slavonski Brod,

35000 Slavonski Brod, Croatia

E-mail: jcumin@unisb.hr

Ivan SAMARDŽİ́, PhD. Eng, full professor

Mechanical engineering faculty in Slavonski Brod,

University of Slavonski Brod

35000 Slavonski Brod, Croatia

E-mail: isamardzic@unisb.hr 